\title{
Predictors of oral health-related quality of life in 2-5 year-old children in the South of Iran
}

\author{
Masoumeh Abbasi-Shavazi ${ }^{1}$, Elham Mansoorian² ${ }^{*}$ (D), Sara Jambarsang ${ }^{3}$, Amene Hosseini-Yekani ${ }^{4}$ \\ and Vahid Rahmanian ${ }^{5}$
}

\begin{abstract}
Background: Dental and oral diseases can have negative impacts on children's quality of life. The aim of this study was to determine the predictors of oral health-related quality of life (OHRQoL) in the children aged 2-5 years old.

Materials and methods: A total number of 288 children aged between 2 and 5 years were selected and stratified by gender from three community health centres located in the city of Jahrom, south of Fars Province, Iran. The data collection tool was a researcher-made questionnaire whose validity and reliability was confirmed. The questionnaire was completed by parents/caregivers of the children. A multiple linear regression analysis was performed with quality of life as the dependent variable and, based on covariance structural analysis, evaluated the goodness of fit of the resulting structural equations models.

Results: The results showed that predisposing factors with a coefficient of $0.0457(p=0.015)$ and reinforcing factors ones with a coefficient of $0.2748(p<0.001)$ were correlated with the oral health behaviours. Moreover, there was a relationship between such behaviours with a coefficient of $0.1612(p<0.001)$ and oral health status and the given status with a coefficient -0.9714 was correlated with OHRQoL $(p<0.001)$. Based on the covariance structural analysis, the resulting model was found to exhibit a reasonable goodness of fit.

Conclusion: The predictors of the children's OHRQoL included predisposing, strengthening, oral health behaviours and oral health status. Therefore, planning to enhance supportive family behaviours and to boost predisposing factors including knowledge, attitudes, perceived benefits, and self-efficacy in parents and their oral health behaviours is recommended.
\end{abstract}

Keywords: Quality of life, Preschool child, Educational models, Structural equation modelling, Jahrom

\section{Introduction}

Dental and oral diseases can have negative impacts on children's health and mental well-being as well as their families. It can also cause pain and discomfort in this age group. Furthermore, the given diseases can put limits on the activities of individuals at school, or home and

*Correspondence: Elham.mansoorian@gmail.com

${ }^{2}$ Department of Health Education and Promotion, School of Public Health, Shahid Sadoughi University of Medical Sciences, Yazd, Iran

Full list of author information is available at the end of the article consequently waste significant time of study throughout the world $[1,2]$.

Dental caries is the most commonly reported oral/ chronic health disease in children [3, 4]. This disease has been further recognized as a pandemic whose prevalence rates in children in the European countries, the UK, Japan, Asia, Africa, the Middle East, and Indonesia, have been reported by $40 \%, 12 \%, 25 \%, 36-85 \%, 38-45 \%$, $22-61 \%$, and $90 \%$ respectively. The given values in Iran, Senegal, and Thailand have been also at the range of $50-60 \%[5]$. original author(s) and the source, provide a link to the Creative Commons licence, and indicate if changes were made. The images or other third party material in this article are included in the article's Creative Commons licence, unless indicated otherwise in a credit line to the material. If material is not included in the article's Creative Commons licence and your intended use is not permitted by statutory regulation or exceeds the permitted use, you will need to obtain permission directly from the copyright holder. To view a copy of this licence, visit http://creativecommons.org/licenses/by/4.0/. The Creative Commons Public Domain Dedication waiver (http://creativeco mmons.org/publicdomain/zero/1.0/) applies to the data made available in this article, unless otherwise stated in a credit line to the data. 
The World Health Organization (WHO) recognizes dental health and oral hygiene as a one which is a part of general health during the lifetime. They also acknowledged that poor dental health and oral hygiene, as well as untreated illnesses, can have their own profound impacts on quality of life (QoL) in the communities [6].

QoL is a broad concept that is complexly affected by physical, mental and social health [7]. Evaluating the impacts of dental health and oral hygiene on QoL, especially in young children, is of utmost importance because dental and oral conditions can affect growth, weight, self-confidence, socialization, learning abilities and daily activities of children and parents $[8,9]$. Moreover, treatment of oral disease is extremely costly and is ranked as the fourth most expensive disease to treat in most developed countries. In low-income countries, if treatment was available, the costs of dental caries alone in children would exceed the total health care budget for children. [10].

The HRQoL was introduced as a multidimensional subject containing physical, social, and psychological dimensions. The given concept indicates if people are satisfied with their dental health status and if their functioning has been affected or disrupted by this condition [11]. OHRQoL is vital in children because dental and oral diseases are so common in this age group and problems caused by these diseases, especially dental pains or visual problems can have negative impacts on QoL in children at present and the future. It also impacts on their daily routine activities including playing, sleeping habits, nutrition, social participation, and academic performance [12]. In this regard, the findings of the study by Jabbarifar et al. [13] pointed out the unacceptable status of OHRQoL in Iranian children.

As the ultimate goal in children's dental health and oral hygiene is to improve their QoL, the use of a model as a framework for identifying factors related to OHRQoL is important. In this respect, PRECEDE (predisposing, reinforcing, and enabling factors) model provides a systematic process for health planning and evaluation [14]. The predisposing factors are awareness, attitudes, beliefs, convictions, and perceptions of an individual or population that facilitate or hinder motivation to change. The reinforcing factors are related to the reaction of others to a person's behaviour, which can be rewarding or punishing. The enabling factors can manifest themselves as barriers and skills [15]. The capacity of this model to plan, expand, and evaluate interventions has been verified in other studies [16-18].

PRECEDE phase constitutes of five stages: (1) social diagnosis, (2) epidemiological diagnosis, (3) behavioural and environmental diagnosis, (4) educational and organizational diagnosis and (5) administrative and political diagnosis [18]. Applying the actions outlined in stages 1-5 of the PRECEDE phase to perform a cross-sectional survey in a combination of a literature review tried to determine the predictors of OHRQoL in preschool children.

It should be noted that mothers are considered as the main caregivers performing dental health and oral hygiene measures in children aged 1 to 3 years old. Even though the development of children in the domain of oral health and dental hygiene starts in pre-school period (aged 3 to 6 years), mothers are still the main caregivers meeting dental health and oral hygiene needs in children [19]. Therefore, it seems that it is necessary to reflect on predisposing, enabling, and reinforcing factors associated with mothers in terms of evaluating QoL in children [20]. To our best knowledge, no specific study has examined the factors related to OHRQoL in children aged 2-5 years based on this model. Therefore, the purpose of the present study was to determine the predictors of oral health-related quality of life (OHRQoL) in the children aged $2-5$ years old.

\section{Materials and methods Study design and participants}

This cross-sectional study was conducted on a total number of 288 children aged 2 to 5 years. The children referred, by their parents, to the community health centres in the city of Jahrom located in the county of Jahrom, Fars province, Iran, to receive Primary Health Care (PHC) services. The PHC services in response to the global strategy for health for all by the year 2000 is defined. The PHC services in the health system was introduced in Iran in 1985. The PHC services in this system are free of charge.

The sample unit was selected and stratified by gender from three community health centres. The required sample sizes were calculated using a similar study [16] including 95\% confidence level, 6.8 standard deviation and 0.78 margin of error.

The inclusion criteria in this study were an agreement to participate in the study as well as the presence of baby teeth in a child and the absence of permanent ones in children. These children were required to be geographically located inside the area under the coverage of healthcare services provided by community healthcare centres. This study has excluded parents (fathers, mothers, or child caregiver) who were not willing to participate in the study, children and parents who disliked clinical examinations. The exclusion was also extended to the children aged 2-5 years who had previously received dental and oral healthcare services (varnishing and fluoride therapy) in private kindergartens and private dental clinics. 
The data collection instrument was a questionnaire comprised of three parts; demographic characteristics (child's age, gender, birth order, number of children in a family, parents' age, education and occupation, child-parent relationships, and the household income), OHRQoL scale, and constructs of PRECEDE model associated with OHRQoL in children aged 2 to 5 years. To determine the validity of the questionnaire, Content Validity Ratio (CVR) and Content Validity Index (CVI) were used and ultimately items with CVR of higher than 0.99 and CVI of over 0.78 were chosen. Furthermore; adherence to grammar, use of proper words, the importance of items, positioning items in suitable places, and necessary time to complete the questionnaire were evaluated and approved by experts of health education. Moreover, the internal validity or reliability of the designed instruments was confirmed by calculating the Cronbach's alpha coefficient over 0.72 , about the cut-off point of 0.65 [21] (Additional file 1).

\section{Data collection instrument}

To evaluate OHRQoL, we used the Early Childhood Oral Health Impact Scale (ECOHI). This instrument has translated and culturally adapted to assess OHRQoL of preschool children in some communities [22-25]. Jabarifar et al. [22] translated this questionnaire into Persian and Proved in a study in 2-5 years old children, that the Persian version of ECOHI for assessing OHRQoL of preschool children has appropriate validity and reliability.

The research instrument is comprised of 13 items in two general categories; the first 9 items address children's oral health status and its impacts including symptoms of the disease, child's functioning, mental-psychological health status, self-confidence, and social interactions. The last four items examine the effect of children's oral health status on their families, which consists of family concerns and its functions. Each answer to these 13 items was scored based on Likert scale, score one (never) to score five (frequently). The higher scores attributed to each child indicated lower OHRQoL. Moreover, answers to items with "I don't know" as well as unanswered items were considered as mean total scores obtained by each individual from one to 13. Generally, the total scores of this index have range of $13-65$, which the scores range 13-29 good, 30-47 fair and 48-65 "poor" [22].

In the next step, the questionnaire was designed based on the PRECEDE model. The PRECEDE variables included oral health status, oral health behaviours, predisposing factors, reinforcing factors and enabling factors, which are described as follows:

Self-report questionnaire (researcher-made) for oral health status was also utilized to evaluate the oral health status. The questionnaire consists of four questions including assessing the child's oral health status from the parents' point of view (very bad/bad/good/very good/I do not know), awareness of decayed teeth (yes/no/not sure), frequency of dental caries and cleaning teeth after brushing (yes/no/I don't know) which was ultimately scored between 0 and 7 . The lower score obtained from this questionnaire indicated the lower oral health status.

To evaluate oral health behaviours, a questionnaire with seven items was developed in which children's brushing behaviours, parental monitoring methods used for children's brushing behaviours, sugar consumption (chocolate, sweets, and sweetened beverages) by children and limiting these substances by parents included. The visits to dentists and gaining information about dental and oral health were also evaluated with scores ranged between 0 and 16. In this respect, a higher score could reflect more favourable oral health behaviours in the children.

To assess the predisposing factors, the variables of knowledge, attitude, perceived barriers, perceived benefits, parental self-efficacy, oral health behaviour of parents were evaluated.

Parental knowledge about children's dental health status was evaluated through a seven item questionnaire scored from zero to seven in which a higher score indicated more knowledge. Parents' attitudes towards children's dental health status were also evaluated by 18 items with a three-points Likert-type scale including "disagree", "neutral", and "agree" and scored from 18 to 54 in which a higher score showed more favourable attitudes. Perceived barriers to children's dental health and oral hygiene were evaluated using 16 items with a three-points Likert-type scale including "at all", "somewhat", and "often". The scores ranged from zero to 32 and a higher score reflected more perceived barriers by parents. Nine items with a threepoints Likert-type scale from "disagree", "neutral" and "agree" were utilized to evaluate perceived benefits associated with dental health and oral hygiene. The scores ranged between 9 and 27 and a higher score represented higher perceived benefits by the parents. Parental selfefficacy regarding dental health and oral hygiene was also evaluated by six items using a 3-point Likert-type scale of "at all", "somewhat", and "often" scored between zero to 12 in which higher scores showed more parental self-efficacy. To evaluate the oral health behaviours in parents; a four-item questionnaire was used which ranged between zero to 12 and the higher scores indicating better functioning and welfare.

The enabling factors were similarly evaluated using 11 items with a 3-point Likert-type scale from "never", "somewhat", "often" with a score range from zero to 22 in which higher scores indicated more access to dental health and oral hygiene resources and amenities. 
Furthermore, the reinforcing factors were evaluated by assessing supportive family behaviours via six items with a three-point Likert-type scale ranging from "at all" to "often", scored between zero to 12, in which higher scores showed more support by spouse and children.

\section{Statistical analysis}

After collecting the data and coding the questionnaires, they were imported into the Stata software (version 14) and then analysed using descriptive (frequency tables, mean and standard deviation) and analytical (Kolmogrov-Smirnov test for check the normality, Kruskal-Wallis tests) statistics. Multiple linear regression analysis was necessary to elucidate the factors by which the dependent variables might potentially be influenced, and to what extent. In the next step, structural equation modelling (SEM) was employed to examine the relationships between the PRECEDE model constructs.

In this model, three steps were considered as follows: In step 1, Oral health behaviours were considered as a dependent variable and predisposing, reinforcing and enabling factors were considered as an independent variable. Under step 2, Oral health status was considered a dependent variable and oral health behaviours was considered an independent variable and in the third step OHRQoL was considered as a dependent variable and oral health status was considered as an independent variable.

It should be noted that SEM is a general and strong multivariate analysis technique from the regression family, i.e., it is an extension of general linear model testing a set of regression equations simultaneously. The goodness of fit of the model was evaluated based on the $x^{2}$, goodness of fit index (GFI), adjusted goodness of fit index (AGFI). Acceptable goodness of fit was defined as $\chi^{2} / d f<3.0$, GFI $>0.90$, AGFI $>0.85$ [23]. The significance level was also considered by 0.05 .

\section{Results}

The total number of 288 children referred to community health centres to receive PHC services were enrolled in this study. As summarised in Table 1, 238 (82.6\%) of the questionnaires were completed by the mothers. In terms of the age group the classification was as follows: 73 children (25.3\%) between 24 and 25 months old, 81 of them (28.1\%) aged 36-47 months old, 79 of them (27.4\%) aged between 48 and 49 months old, and 55 of them (19.2\%) aged between 71 and 60 months. Concerning the gender, 148 girls $(51.4 \%)$ and 179 children $(62.2 \%)$ were the firstborn babies in their family. In terms of the number of children in a family, 112 children (38.9\%) were only-child and 87 of them $(30.2 \%)$ were the second-born. Considering parental age, the highest frequency of father's age was
208 individuals (72.2\%) in the age group of $31-40$ years and for the case of mother's age that was 159 individuals $(55.2 \%)$ for the age group of $31-40$ years. The highest level of education among fathers included 105 individuals (36.5\%) with high school diploma and the given frequency was 109 mothers (37.8\%) holding bachelor's degrees (see Table 1).

Moreover, a significant difference was observed between the mean score of oral health behaviours in terms of age groups $(p=0.001)$, but such a difference was not significant based on gender $(p=0.60)$. Besides, there was no difference in the mean scores of OHRQoL, oral health status, predisposing factors, reinforcing factors, and enabling factors in terms of age and gender groups groups $(p>0.05)$ (see Table 2$)$.

The PRECEDE model proportional to the study population resulted from the SEM-based path analysis is illustrated in Fig. 1.

The findings of this model showed that the predisposing factors with a coefficient of 0.0457 were correlated with oral health behaviours $(p=0.015)$. There was also the correlation between reinforcing factors with a coefficient of 0.2748 and oral health behaviours $(p<0.001)$. The oral health behaviours with a coefficient of 0.1612 were also correlated with oral health status $(p<0.001)$. Moreover, a correlation was observed between oral health status with a coefficient of 0.9714 and OHRQoL $(p<0.001)$ (see Table 3). Measures of model fit $\left(x^{2} / d f=1.475\right.$, $\mathrm{GFI}=0.916$, AGFI $=0.863$, indicated that the model had an acceptable goodness of fit.

\section{Discussion}

The purpose of this study was to determine the predictors of OHRQoL in children aged 2-5 years using the PRECEDE model. Based on the findings of this study, the predictors of the children's OHRQoL included predisposing, strengthening, oral health behaviours and oral health status.

Based on the findings of this study, the mean score of OHRQoL in children was reported good which was consistent with the results of the study by Jabbarifar et al. [23] in the city of Shiraz as the capital of Fars Province, Iran. This consistency may be attributed to the closeness of Shiraz and Jahrom where the people almost follow the same pattern in terms of culture and diet style. Moreover, children's oral health status in this study was evaluated at a moderate level which was in line with the findings of the investigation by Ghazanfari et al. [20] on 3- to 6-yearold children in the city of Ilam, Iran. This implies that the parents had evaluated their children's status in terms of dental caries and satisfaction with cleaning as well as their dental health and oral hygiene at a moderate level (within due or reasonable limits). 
Table 1 Frequency distribution of demographic variables of the study participants

\begin{tabular}{|c|c|c|c|}
\hline Variable & Item & Absolute frequency & $\begin{array}{l}\text { Relative } \\
\text { frequency } \\
(\%)\end{array}$ \\
\hline \multirow[t]{3}{*}{ Respondents } & Mother & 238 & 82.6 \\
\hline & Father & 46 & 16 \\
\hline & Child's caregiver & 4 & 1.4 \\
\hline \multirow[t]{4}{*}{ Child's age } & 24-35 months & 73 & 25.3 \\
\hline & 36-47 months & 81 & 28.1 \\
\hline & $48-59$ months & 79 & 27.4 \\
\hline & 60-71 months & 55 & 19.2 \\
\hline \multirow[t]{2}{*}{ Child's gender } & Female & 148 & 51.4 \\
\hline & Male & 140 & 48.6 \\
\hline \multirow[t]{3}{*}{ Birth order } & First-born & 179 & 62.2 \\
\hline & Second-born & 87 & 30.2 \\
\hline & Third-born and higher & 22 & 7.6 \\
\hline \multirow[t]{3}{*}{ Number of children in a family } & Only child & 112 & 38.9 \\
\hline & 2-3 children & 160 & 55.6 \\
\hline & 4-5 children & 16 & 5.5 \\
\hline \multicolumn{4}{|l|}{ Parental age } \\
\hline \multirow[t]{4}{*}{ Father } & Below 30 years old & 30 & 10.4 \\
\hline & $31-40$ years old & 208 & 72.2 \\
\hline & $41-50$ years old & 44 & 15.3 \\
\hline & Over 50 years old & 6 & 2.1 \\
\hline \multirow[t]{3}{*}{ Mother } & Below 30 years old & 121 & 42 \\
\hline & $31-40$ years old & 159 & 55.2 \\
\hline & $41-50$ years old & 8 & 2.8 \\
\hline \multicolumn{4}{|l|}{ Level of education } \\
\hline \multirow[t]{6}{*}{ Father } & Primary school & 18 & 6.2 \\
\hline & Middle school & 53 & 18.4 \\
\hline & High school diploma & 105 & 36.5 \\
\hline & Associate's degree & 21 & 7.3 \\
\hline & Bachelor's degree & 67 & 23.3 \\
\hline & Master's degree and higher & 24 & 8.3 \\
\hline \multirow[t]{6}{*}{ Mother } & Primary school & 12 & 4.2 \\
\hline & Middle school & 19 & 6.6 \\
\hline & High school diploma & 106 & 36.8 \\
\hline & Associate's degree & 23 & 8 \\
\hline & Bachelor's degree & 109 & 37.8 \\
\hline & Master's degree and higher & 19 & 6.6 \\
\hline \multirow[t]{5}{*}{ Father's occupation } & Employee & 82 & 28.5 \\
\hline & Worker & 37 & 12.8 \\
\hline & Self-employed & 159 & 55.2 \\
\hline & Retired & 2 & 0.7 \\
\hline & Other & 8 & 2.8 \\
\hline \multirow[t]{4}{*}{ Mother's occupation } & Housewife & 237 & 82.3 \\
\hline & Work from home & 4 & 1.4 \\
\hline & Employed outside the home & 42 & 14.6 \\
\hline & Other & 5 & 1.7 \\
\hline
\end{tabular}




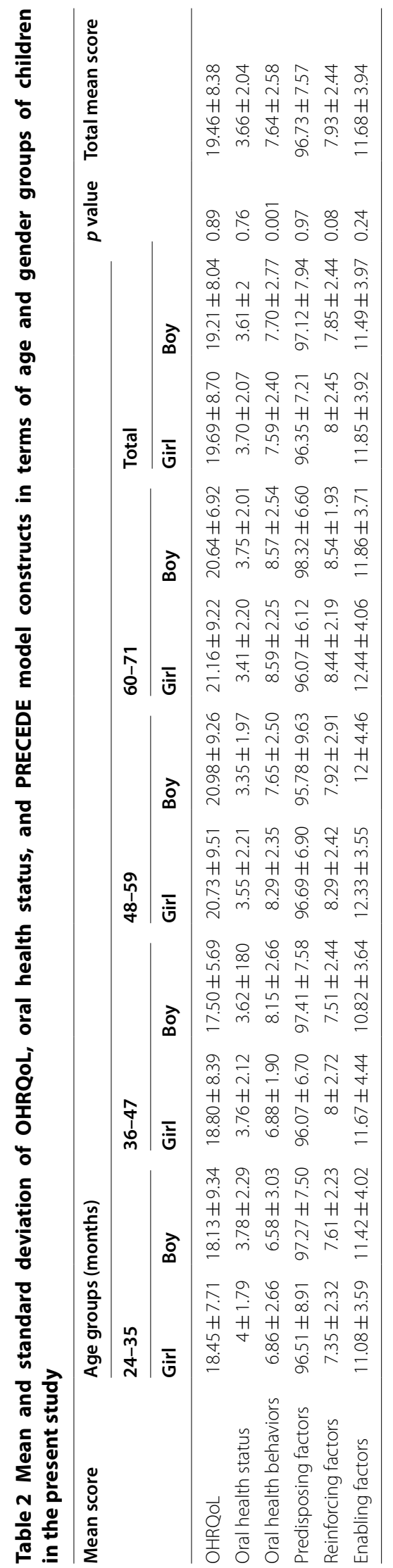




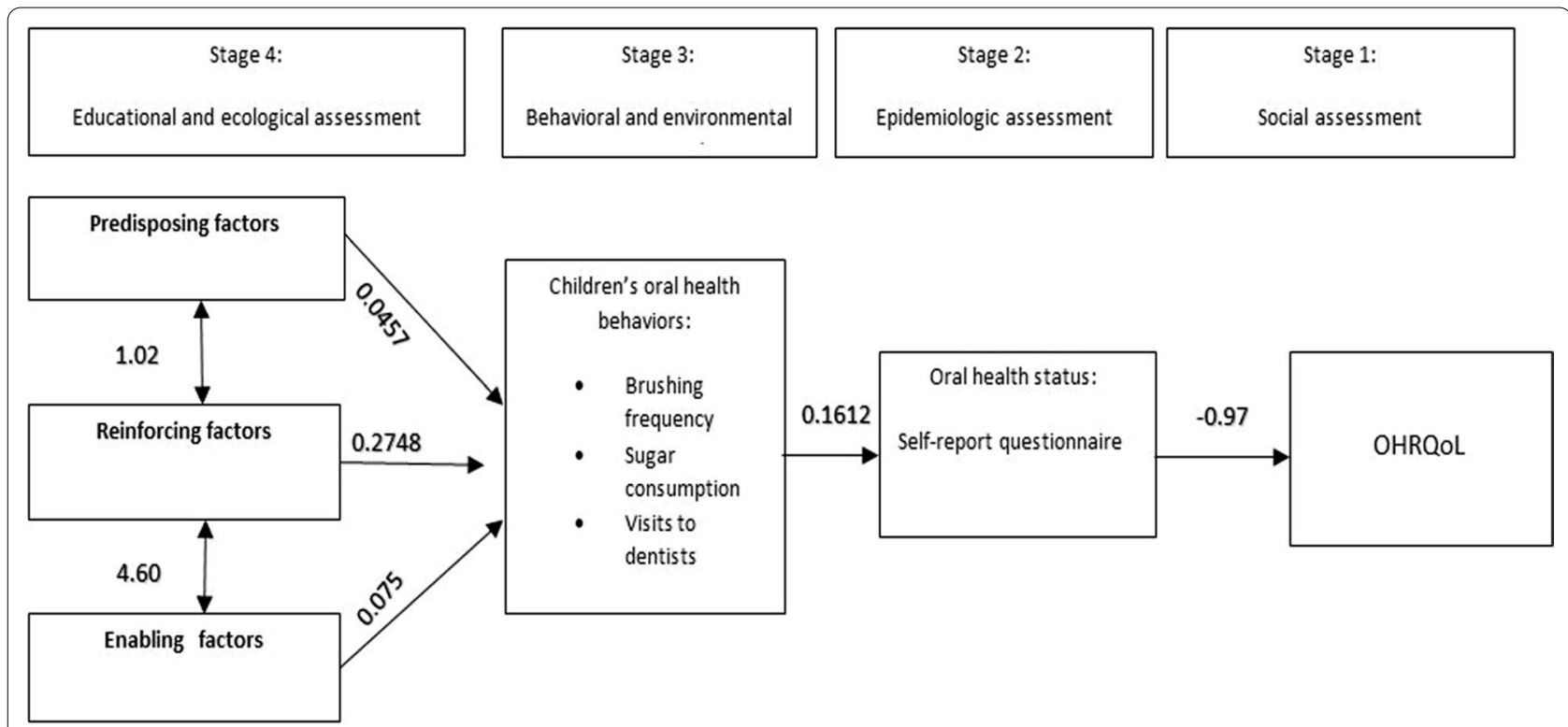

Fig. 1 Predictors of OHRQOL in children based on the results of path analysis of PRECEDE model constructs

Table 3 SEM results for examining relationships between PRECEDE model constructs

\begin{tabular}{|c|c|c|c|c|c|}
\hline & \multirow[t]{2}{*}{ SEM coefficient } & \multirow{2}{*}{$\begin{array}{l}\text { Standard } \\
\text { deviation }\end{array}$} & \multirow[t]{2}{*}{ Significance level } & \multicolumn{2}{|c|}{$95 \%$ confidence interval } \\
\hline & & & & Low & High \\
\hline \multicolumn{6}{|l|}{ Oral health behaviours } \\
\hline Predisposing factors & 0.0457 & 0.0188 & 0.015 & 0.0088 & 0.0826 \\
\hline Reinforcing factors & 0.2748 & 0.0659 & 0.001 & 0.1455 & 0.4041 \\
\hline Enabling factors & 0.0750 & 0.0410 & 0.068 & -0.0054 & 0.1555 \\
\hline \multicolumn{6}{|l|}{ Oral health status } \\
\hline Oral health behaviours & 0.1612 & 0.0445 & 0.001 & 0.07196 & 0.2504 \\
\hline \multicolumn{6}{|l|}{ OHRQOL } \\
\hline Oral health status & -0.9714 & 0.2349 & 0.001 & -1.431 & -0.5109 \\
\hline Covariance for predisposing and reinforcing factors & 1.025 & 1.090 & 0.347 & -1.111 & 3.162 \\
\hline Covariance for predisposing and enabling factors & 2.917 & 1.763 & 0.098 & -0.539 & 6.373 \\
\hline Covariance for reinforcing and enabling factors & 4.601 & 0.628 & 0.001 & 3.369 & 5.833 \\
\hline
\end{tabular}

In the present study, the mean score of oral health behaviours in children was lower than the average. In this respect, the findings of this study were consistent with those reported by Nokhostin et al. [24], Dehvari et al. [25] and Yavari et al. [26]. As the evaluation of oral health behaviours in this study included brushing, sugar consumption, and visits to dentists and because children in this age group follow mainly their parents, therefore empowering parents through providing information and education in the domain of dental health oral hygiene and teaching skills can help to improve oral health behaviours for the children.
Besides, the results of this study showed that the oral health behaviours in children were significantly correlated with predisposing factors which were in line with the findings of Malek Mohammadi et al. [27] focused on the city of Kerman which is the neighbouring province to Fars. Moreover, these results confirmed the PRECEDE model assumption implying a direct relationship between predisposing factors and behaviours. Since predisposing factors in this study were evaluated through knowledge, attitudes, perceived barriers, benefits, parental self-efficacy, and the oral health behaviours by parents, the relationship between predisposing factors and 
behaviours indicated that promotion of each factor could lead to improvement of the oral health behaviours in the children in three domains of brushing, sugar consumption, and visits to dentists. In this line, the study by Sahraie et al. [28] also showed that maternal knowledge and beliefs about brushing could be among factors acting as barriers to brushing behaviours in children. Wong et al. [29] studied of OHRQoL in Hong Kong focused on preschool children. They showed that parents of young children with dental caries experience, both the children and other family members had poorer quality of life.

The results of this work show that there is a significant relationship between the oral health behaviours in children and reinforcing factors which was confirmed by the PRECEDE model. The reinforcing factors in this model included supportive behaviours by spouse and other children which were in line with the findings of Sahraie et al. [28]. They emphasized the role of family members in children's dental health and oral hygiene and stressed that it is the most important perceived barrier for mothers of 3- to 6-year old children.

It should be noted that the oral health behaviours were not significantly correlated with enabling factors which were in contrast with the findings of the study by Binkley et al. [30] in which dental health and oral hygiene in individuals was significantly correlated with the mental disabilities. There was also a significant relationship between growth impairment and enabling factors which were consistent with the assumption raised by PRECEDE model. In the present study, assessing the enabling factors such as the skill needed to brush a child's teeth, preparing toothbrushes and toothpaste, the cost of transportation for child care and oral care, the cost of dental examinations, insurance payments, health centre staff training done to parents. Measuring enabling factors in a more limited and specific way in the field of children's oral health can be more appropriate.

Other results of this study showed that oral health behaviours were significantly correlated with oral health status. In this regard, the findings of the study by Moalemi et al. [31] conducted in the city of Tehran, Iran, suggested that the oral health behaviours in 9-year-old primary school children were correlated with the oral health status. Our results were in agreement with the PRECEDE model assumption in which a direct relationship between predisposing factors and behaviours had been highlighted. Since the oral health status, frequency of dental caries, and dental health and oral hygiene in children were evaluated from the perspectives of parents in this study, the presence of such a relationship could imply that the way parents had evaluated children's brushing, sugar consumption, and visits to dentists could influence their oral health status.
Based on the findings of this work, the oral health status had a direct impact on OHRQoL. It means that improving the oral health status could enhance OHRQoL which was consistent with the findings of the study by Saleki et al. [32] in Iran. Saho et al. [33] in the study of structural equation modelling to detect predictors of oral health-related quality of life in Japan showed that oral health status was directly associated with the OHRQoL. Furthermore, Rodolfo et al. [1] reported that dental caries, mobile milk teeth, tooth position, bleeding gums, and bad breath were associated with the wors OHRQoL children in Rio de Janeiro. Moreover, the given results confirmed the PRECEDE model assumption underlining a direct relationship between predisposing factors and the behaviours.

Based on the results of this study, reinforcing and enabling factors were significantly interrelated, confirming the PRECEDE model assumption in which interrelationship between reinforcing and enabling factors was confirmed. Therefore, planning interventions for strengthening any of the above factors could lead to mutual improvement. Additionally, educating parents as well as providing them with the right information about the areas of oral/dental health and also educate them the required skills as predisposing factors could lead to improve the reinforcing factors.

Binkley et al. [30] in the study of using PRECEDEPROCEED planning model in designing an oral health strategy united states, showed that PRECEDE-PROCEED planning model can be used for planning, development and evaluation of interventions in oral health.

The strengths of the present study are its exploratory approach towards designing the research instrument in which CVR and CVI were measured as a tool to evaluate parents' perceptions more objectively.

The limitations of this study were the self-assessing of life-scale related to the oral health and other factors related to the pattern asked by the parents which can be effective in external validity the results of this study. Therefore, evaluating dental health status using objective scales including dmft and Modified Gingival Index (MGI) could have positive impact on making these studies and their results more objective. Also, the outcome of this study can be generalized that the quality of life associated with oral health for the children who contact the health centres for primary health care services may be different from those who do not receive these care services.

\section{Conclusion}

The predictors of the children's OHRQoL included predisposing, strengthening, oral health care behaviours and oral health status. Therefore, proper planning to improve family behaviours and strengthening 
the predisposing factors such as knowledge, attitudes, perceived benefits, parental self-efficacy and their oral health status, as well as reducing perceived barriers can enhance children's oral health behaviours and consequently promote the oral health status and OHRQoL in children aged 2-5 years. Considering elements of the PROCEDE model in interventions aimed at enhancing oral health status in children might be valuable and therefore, worth investigating in future research.

\section{Supplementary information}

Supplementary information accompanies this paper at https://doi. org/10.1186/s12955-020-01587-7.

Additional file 1. Early Childhood Oral Health Impact Scale (ECOHI).

\section{Acknowledgements}

This study was derived from a Master's Thesis in Health Education and Health Promotion from Shahid Sadoughi University of Medical Sciences, Yazd, Iran. The authors would like to sincerely appreciate all parents and children who collaborated in this study.

\section{Authors' contributions}

The initial idea of this study was by EM. EM and VR contributed to the design and management of the study and writing of the manuscript and implementing all comments from the reviewers. SJ participated in the statistical analysis. MAS and VR contributed to the writing of the manuscript. AHY contributed to questionnaire design, edition, and revision. MAS and VR contributed to the translation of the manuscript. All authors read and approved the final manuscript.

\section{Funding}

This study was funded by the Yazd University of Medical Science, Iran.

\section{Availability of data and materials}

The data are available upon request from the corresponding author.

\section{Ethics approval and consent to participate}

The ethical considerations of the study such as the required information about the research objectives, voluntary participation in the study, and confidentiality of data were fully explained to the parents. After the completion of the consent forms by parents, they received the questionnaires and their children were subsequently examined. It should be noted that the present study was approved by the Ethics Committee of the Vice-Chancellor's Office for Research at Shahid Sadoughi University of Medical Sciences, Yazd, Iran; with the code of ethics: IR.SSU.SPH.REC.1397.109.

\section{Consent for publication}

Not applicable.

\section{Competing interests}

The authors would like to declare that there is no conflict of interest regarding the publication of this article.

\footnotetext{
Author details

1 Department of Health Education and Promotion, School of Public Health, Shahid Sadoughi University of Medical Sciences, Yazd, Iran. ${ }^{2}$ Department of Health Education and Promotion, School of Public Health, Shahid Sadoughi University of Medical Sciences, Yazd, Iran. ${ }^{3}$ Research Center of Prevention and Epidemiology of Non-Communicable Disease, Department of Biostatistics and Epidemiology, School of Public Health, Shahid Sadoughi University of Medical Sciences, Yazd, Iran. ${ }^{4}$ School of Dentistry, Shahid Sadoughi University of Medical Sciences, Yazd, Iran. ${ }^{5}$ Research Center for Social Determinants of Health, Jahrom University of Medical Sciences, Jahrom, Iran.
}

Received: 23 September 2019 Accepted: 29 September 2020

Published online: 11 December 2020

\section{References}

1. Castro RA, Portela MC, Leão AT, de Vasconcellos MT. Oral health-related quality of life of 11-and 12-year-old public school children in Rio de Janeiro. Commun Dent Oral Epidemiol. 2011;39:336-44.

2. Mohammadi M, Vaisi A, Jalali R, Ghobadi A, Salari N. The prevalence of dental caries in deciduous and permanent teeth in Iranian children: a systematic review and meta-analysis. J Res Dent Sci. 2018;15(3):181-90.

3. Mouradian WE, Slayton RL, Maas WR, Kleinman DV, Slavkin H, DePaola D, Evans C Jr, Wilentz J. Progress in children's oral health since the surgeon general's report on oral health. Acad Pediatr. 2009;9:374-9.

4. Hazavehei SMM, Shirahmadi S, Taheri M, Noghan N, Rezaei N. Promoting oral health in 6-12 year-old students: a systematic review. J Educ Commun Health. 2015;1:66-84.

5. WHO. Oral health. https://www.who.int/oral_health/publications/facts heet/en/. Accessed 20 Feb 2019.

6. Torabi M, Karimi A, Sheikhzadeh A, Karimi AM. Assessment of oral health indices in Kerman adults aged 35-44 years. J Isfahan Dent Sch. 2009;5:93-8.

7. Akhter R, Hassan NMM, Martin EF, Muhit M, Smithers-Sheedy H, Badawi $\mathrm{N}$, Khandaker G. Caries experience and oral health-related quality of life (OHRQoL) of children and adolescents with cerebral palsy in a lowresource setting. BMC Oral Health. 2019;19:15.

8. Tomazoni F, Vettore MV, Mendes FM, Ardenghi TM. The Association between sense of coherence and dental caries in low social status school children. Caries Res. 2019;53:314-21.

9. Amirabadi F, Saravani S, Miri-Aliabad G, Khorashadi-Zadeh M. The Association between dental health status and oral health-related quality of life of children diagnosed with $\beta$-Thalassemia Major in Zahedan City, Iran. Int J Pediatr. 2019;7:8985-91.

10. Suprabha BS, Rao A, Shenoy R, Khanal S. Utility of knowledge, attitude, and practice survey, and prevalence of dental caries among 11- to 13-year-old children in an urban community in India. Glob Health Action. 2013;6:20750

11. Hillebrecht A-L, Hrasky V, Anten C, Wiegand A. Changes in the oral healthrelated quality of life in adult patients with intellectual disabilities after dental treatment under general anesthesia. Clin Oral Investig 2019:1-9.

12. Masumo RM, Ndekero TS, Carneiro LC. Prevalence of dental caries in deciduous teeth and oral health related quality of life among preschool children aged 4-6 years in Kisarawe. Tanzan BMC Oral Health. 2020;20:46.

13. Jabarifar SE, Khadem P, Ahmadi S, Hajiahmadi M, Nilchian F. Assessment of psychometric projection of the Persian version of the Child Perception Questionnaire (CPQ8-10) in 8-10 year-old students in Isfahan. J Isfahan Dent Sch. 2011a;6:165-72.

14. Mohammadizeydi E, Farmanbar R, Asadpur M, Noroozi A, Rahmati F, Ghazanfari Z, Aamidi M, Rahnama P. The precede-proceed model. In: Ghofranipur F, editor. Pattern change behavior. Tehran: Tarbiat Modares University; 2006. p. 57-92

15. Green L, Kreuter M. Health program planning: an educational and ecological approach. 4th ed. San Francisco: McGraw-Hill; 2005.

16. Golkari A, Moeini A, Jabarifar SE. Relationship of socioeconomic status with quality of life related to oral and dental health of 2-5-year-olds in Shiraz. J Isfahan Dent Sch. 2014;9:534-41.

17. Nadrian H, Morowatisharifabad MA, Bahmanpour K. Development of a rheumatoid arthritis education program using the PRECEDE_PROCEED model. Health Promot Perspect. 2011;1:118.

18. Nadrian H, Morowati Sharifabad MA, Soleimani SH. Paradims of rheumatoid arthritis patients quality of life predictors based on path analysis of the Precede model. Hormozgan Med J. 2010;14:32-44.

19. Naderifar M, Akbarsharifi T, Pairovi H, Haghani H. Mothers'awareness, regarding orodental health of their children at age of 1-6 years old. Iran J Nurs. 2006;19:15-27.

20. Esmailikia M, Gholami Parizad E, Abedzadeh Zavareh MS, Sayehmiri K, Ghazanfari Z. Prediction of oral health in children 3-6 years old in Ilam, 2015: application of health belief model. J Ilam Univ Med Sci. 2016;24:49-58. 
21. Sim J, Wright C. Research in health care. Cheltenham: Nelson Thornes Ltd; 2000.

22. Jabarifar SE, Khadem P, Ahmadi S, Hajiahmadi M, Nilchian F. Assessment of psychometric projection of the Persian version of the Child Perception Questionnaire (CPQ8-10) in 8-10 year-old students in Isfahan. J Dent Sch. $2011 \mathrm{~b} ; 6: 165-72$.

23. Nakamura H, Watanabe N, Matsushima E. Structural equation model of factors related to quality of life for community-dwelling schizophrenic patients in Japan. Int J Ment Health Syst. 2014:8:32.

24. Nokhostin MR, Siahkamari A, Akbarzadeh BA. Evaluation of oral and dental health of 6-12 year-old students in Kermanshah city. Iran South Med J. 2013;16:241-9.

25. Dehvari M, Ghaneian MT, Morowatisharifabad MA, Karimi M, Jasemizad T. Knowledge, attitudes and practice of women about adverse effects of cosmetics in Yazd City. Iran Health Scope. 2018;7:e68257.

26. Yavari M, Morowatisharifabad M, Haghi M, Rezaeipandari H, Hatamzadeh $\mathrm{N}$, Azad E. Study of knowledge, attitude, practice and oral health status among high school students in Yazd. Tolooebehdasht. 2016;14:261-75.

27. Naidu R, Nunn J, Donnelly-Swift E. Oral health-related quality of life and early childhood caries among preschool children in Trinidad. BMC Oral Health. 2016;16:128.

28. Sahrayi P, Keshavarz Mohammadi N, Ghasemi H. Perceived barriers of mothers in brushing the teeth of their 3-6 years old children, a qualitative study. Iran J Pediatr Dent. 2015;10:45-62.
29. Wong H, McGrath C, King N, Lo E. Oral health-related quality of life in Hong Kong preschool children. Caries Res. 2011:45:370-6.

30. Binkley CJ, Johnson KW. Application of the PRECEDE-PROCEED planning model in designing an oral health strategy. J Theory Pract Dent Public Health 2013;1.

31. Rando GM, Jorge PK, Vitor LLR, Carrara CFC, Soares S, Silva TC, Rios D, Machado M, Gavião MB, Oliveira TM. Oral health-related quality of life of children with oral clefts and their families. J Appl Oral Sci Rev FOB. 2018:26:e20170106

32. Saleki M, Jabbarifar SE, Soheilipour S, Hajjizadeh F. Assessing the sensitivity and responsiveness of Early Childhood Oral Health Impact Scale to routine dental treatments on life quality of preschool children in Isfahan in 2011. J Isfahan Dent Sch. 2012;7:688-97.

33. Saho H, Ekuni D. Structural equation modeling to detect predictors of oral health-related quality of life among Japanese university students: a prospective cohort study. Qual Life Res. 2019;28:3213-24.

\section{Publisher's Note}

Springer Nature remains neutral with regard to jurisdictional claims in published maps and institutional affiliations.
Ready to submit your research? Choose BMC and benefit from:

- fast, convenient online submission

- thorough peer review by experienced researchers in your field

- rapid publication on acceptance

- support for research data, including large and complex data types

- gold Open Access which fosters wider collaboration and increased citations

- maximum visibility for your research: over $100 \mathrm{M}$ website views per year

At BMC, research is always in progress.

Learn more biomedcentral.com/submissions 